\title{
EDITORIAL
}

\section{Exposure science perspective on disaster preparedness and resilience}

(c) The Author(s), under exclusive licence to Springer Nature America, Inc. 2021

Journal of Exposure Science \& Environmental Epidemiology (2021) 31:795-796; https://doi.org/10.1038/s41370-021-00381-x

"...there is no time for delay and no room for excuses." (Antonio Guterres, United Nations Secretary-General, August 9, 2021 [1])

The summary of the $6^{\text {th }}$ Assessment Report (6AR) of the Intergovernmental Panel on Climate Change [2] indicated once more that sea levels continue to rise, and extreme weather patterns are the main climate change-related threats to human health and the environment. Disasters related to extreme weather events, wildland fires, and outbreaks of infectious disease, and industrial accidents are increasingly impacting community wellbeing and population health.

Exposure science is advancing to support disaster preparedness, emergency response, and mitigation of impacts in the after math of both man-made and natural disasters [3]. Contributions in this special topic issue address exposures across temporal and geographical dimensions for a range of natural and man-made disasters. Reported results consider exposure and health impact information collected in an early phase by search and rescue teams, during the incident from victims and existing monitoring systems, as well as during the aftermath.

The safety of first responders is assessed prior to entering the affected area for search and rescue (S\&R) operations. This assessment is the first opportunity to collect data for exposure and risk assessment. In general, exposure assessment for the S\&R activity requires swift and timely results to support on-scene commanders and coordinators. Once the first responders are active in the disaster area they collect and share additional information via situation reports and visual recordings such as videos from drones.

Exposure data is vital to enable modelling for mitigation of the impact in emergency settings, e.g. Computer-Aided Management of Emergency Operations (CAMEO). For hazardous substances an atmospheric dispersion model can be used for evaluating releases of hazardous chemical vapours (ALOHA). This software can be used to generate plots that indicate the perimeter of a threat zone with guidance values such as the Acute Exposure Guideline Levels for Airborne Chemicals (AEGLs) and the Emergency Response Planning Guidelines (ERPGs) in the US. The accuracy of these model predictions is limited and the perimeter of the affected area needs verification by observations and measurements by $S \& R$ teams in field.

In addition to information from the first responders, data from existing networks of weather stations are of particular interest during extreme weather events. Regular air monitoring networks provide air quality parameters that may be important for urban areas covered by smoke from wildland fires [4]. These data can be complemented by data from remote sensing systems that generate space and time-resolved data on the impact of largescale incidents $[5,6]$. In extreme events such as massive hurricane or tsunami, blackout of electricity in the affected area can be anticipated. Then, a self-supporting mobile laboratory or aircraft such as Portable High-Throughput Integrated Laboratory Identification System (PHILIS) and Airborne Spectral Photometric Environmental Collection Technology (ASPECT) may play an important role for rapid exposure measurements.

When the acute phase is over, additional data may be collected during the aftermath. Examples of relevant data are related to air quality [7], surface, drinking water, and crop contamination. Health outcomes are studied using different types of outcomes, e.g. reports of emergency room visits, hospital admissions and reports of type and severity of injury, including initial counts of fatalities and missing persons. During the aftermath data may also be collected through crowd research and plotted for the locations from which health complaints are reported.

More detailed quantitative exposure data are most likely not collected until later. Human biomonitoring is a good method for chemical exposure surveillance of first responders like firefighters who respond to chemical incidents in industrial settings [8] or more general settings [9]. Human biomonitoring campaigns may also be used to confirm exposures in a larger group of disaster victims specifically when measurements in environmental compartments are not possible or come too late $[10,11]$. Recently, the Joint Research Center published a flagship report to describe how science informs disaster management [12]. Many exposure-related topics were highlighted as innovations such as human biomonitoring to support emergency response to disasters [13].

During the aftermath of a disaster there may be long-term effects on human health and the environment. The study population is usually defined by survivors still at risk living in the affected area or by those that evacuated themselves or have been evacuated from the disaster area but could still be linked to the disaster e.g., by analysing registries of emergency rooms in healthcare facilities. Exposure and health-oriented studies require additional data collection and modelling to link recruited individuals to locations in the disaster area as verification of their exposure status [14]. When interpreting the impact on humans and the environment it is often difficult to tell which part of the observed impact can be attributed to the disaster, in addition to a history of events also including residues from previous disasters, e.g. during previous floods or other causes in the same area [15]. Registrations of exposure status by the reported health complaints can be inaccurate especially if the complaints are non-specific to the source of exposure. Available biomonitoring data can be useful to verify exposure status and show that hospital visits may provide very limited justification for classification of exposure [16].

For the future, the relevance of exposure assessment is well recognised. The European Commission considers exposure science already in an early phase of emergency response to transboundary disasters by including exposure scientists to an expert panel with a wide range of disciplines relevant to disaster scenarios. In the case of a large incident with cross-border effects, 
a team with expertise considered relevant to the scenario analyses the situation and provides a rapid risk assessment report to the European Commission to support decision making how to provide support related to transboundary aspects $[17,18]$.

In conclusion, exposure science is essential for effective disaster preparedness and response. Exposure scientists are encouraged to collaborate broadly across sectors to advance exposure assessment methods and technologies as well as surveillance and monitoring.

Paul T. J. Scheepers $\mathbb{D}^{1 凶}$ and Shoji F. Nakayama ${ }^{2}$ ${ }^{1}$ Radboud Institute for Health Sciences, Radboudumc, Nijmegen, The Netherlands. ${ }^{2}$ National Institute for Environmental Studies, Tsukuba, Japan.『email: paul.scheepers@radboudumc.nl

\section{REFERENCES}

1. Guterres A. Secretary-General's statement on the IPCC Working Group 1 Report on the Physical Science Basis of the Sixth Assessment. 2021. https://www.un.org/ sg/en/content/secretary-generals-statement-the-ipcc-working-group-1-reportthe-physical-science-basis-of-the-sixth-assessment. Accessed 17 Aug 2021.

2. IPCC. Climate change 2021: the physical science basis. Masson-Delmotte V, Zhai P, Pirani A, Connors SL, Péan C, Berger S, et al. editors. Contribution of Working Group I to the Sixth Assessment Report of the Intergovernmental Panel on Climate Change. Cambridge University Press; 2021. In press.

3. Cardona, OD, van Aalst MK, Birkmann J, Fordham M, McGregor G, Perez R, et al. Determinants of risk: exposure and vulnerability. In: Field, CB, Barros, V, Stocker, TF, Qin, D, Dokken, DJ, Ebi, KL, et al. editors. Managing the risks of extreme events and disasters to advance climate change adaptation; A Special Report of Working Groups I and II of the Intergovernmental Panel on Climate Change (IPCC). Cambridge University Press, Cambridge, UK, and New York, NY, USA, 2012. p. $65-108$

4. Kiser D, Elhanan G, Metcalf WJ, Schnieder B, Grzymski JJ. SARS-CoV-2 test positivity rate in Reno, Nevada: association with PM2.5 during the 2020 wildfire smoke events in the western United States. J Expo Sci Environ Epidemiol. 2021:1-7. https://doi.org/10.1038/s41370-021-00366-w. Epub ahead of print.

5. Vadrevu K, Lasko K. Intercomparison of MODIS AQUA and VIIRS I-band fires and emissions in an agricultural landscape-implications for air pollution research. Remote Sens. 2018;10:978 https://doi.org/10.3390/rs10070978.

6. Gohlke, et al. Health impacts associated with satellite observed flooding following heavy rains caused by Hurricane Harvey over Texas in 2017. 2021. In press.

7. Steenland, et al. Effect modification by temperature of association between PM2.5 and both short-term mortality and morbidity in Lima, Peru, 2010-2016. JESEE. 2021. In press.

8. Bader M, Bäcker S, Jäger T, Webendörfer S, Van Bortel G, Van Mieghem F, et al. Preparedness as a key factor for human biomonitoring programs after chemical incidents. J Expo Sci Environ Epidemiol. 2021. https://doi.org/10.1038/s41370021-00320-w. In press.

9. Jung AM, Zhou J, Beitel SC, Littau SR, Gulotta JJ, Wallentine DD, et al. Longitudinal evaluation of whole blood miRNA expression in firefighters. J Expo Sci Environ Epidemiol. 2021. https://doi.org/10.1038/s41370-021-00306-8. In press.

10. Scheepers PT, Bos PM, Konings J, Janssen NA, Grievink L. Application of biological monitoring for exposure assessment following chemical incidents: a procedure for decision making. J Expo Sci Environ Epidemiol. 2011;21:247-61. https://doi. org/10.1038/jes.2010.4

11. Scheepers PT, van Brederode NE, Bos PM, Nijhuis NJ, van de Weerdt RH, van der Woude I, et al. Human biological monitoring for exposure assessment in response to an incident involving hazardous materials. Toxicol Lett. 2014;231:295-305. https://doi.org/10.1016/j.toxlet.2014.03.002.
12. Casajus Valles A, Marin Ferrer M, Poljanšek K, Clark I editors, Executive summary of the report Science for Disaster Risk Management 2020: acting today, protecting tomorrow, EUR 30183 EN. Luxembourg: Publications Office of the European Union; 2020. https://doi.org/10.2760/919253, JRC114026. https://drmkc.jrc. ec.europa.eu/Knowledge/Science-for-DRM/Science-for-Disaster-RiskManagement-2020. Accessed 29 July 2021

13. Freire S, Petrucci O, Scheepers PTJ, Neuvel JMM, Rocklöv J, Åström C. Threat to life. In: Casajus Valles A, Marin Ferrer M, Poljanšek K, Clark I, editors, Science for Disaster Risk Management 2020: acting today, protecting tomorrow, EUR 30183 EN. Luxembourg: Publications Office of the European Union; 2020. https://doi. org/10.2760/571085, JRC114026. https://drmkc.jrc.ec.europa.eu/Knowledge/ Science-for-DRM/Science-for-Disaster-Risk-Management-2020. Accessed 29 July 2021.

14. Miranda ML, Callender R, Canales JM, Craft E, Ensor KB, Grossman M, et al. The Texas flood registry: a flexible tool for environmental and public health practitioners and researchers. J Expo Sci Environ Epidemiol. 2021 Jun 26:1-9. https:// doi.org/10.1038/s41370-021-00347-z Epub ahead of print.

15. Environmental impacts of Hurricane Florence flooding in eastern North Carolina: temporal analysis of contaminant distribution and potential human health risks. J Expo Sci Environ Epidemiol. 2021. https://doi.org/10.1038/s41370-021-00325-5. Epub ahead of print.

16. Simons K, De Smedt T, Stove C, De Paepe P, Bader M, Nemery B, et al. Short-term health effects in the general population following a major train accident with acrylonitrile in Belgium. Environ Res. 2016;148(Jul):256-63. https://doi.org/ 10.1016/j.envres.2016.03.031.

17. Hague C, Orford R, Gaulton T, Thomas E, Hall L, Duarte-Davidson R. Development of a mechanism for the rapid risk assessment of cross-border chemical health threats. J Expo Sci Environ Epidemiol. 2021. https://doi.org/10.1038/s41370-02100344-2. Epub ahead of print.

18. SCHEER (Scientific Committee on Health, Environmental and Emerging Risks). Guidance on ad hoc rapid risk assessment of serious cross-border chemical threats performed by the SCHEER. Brussels: European Commission; 2017.

\section{ACKNOWLEDGEMENTS}

The authors thank all the contributors to this special issue.

\section{AUTHOR CONTRIBUTIONS}

PS prepared the first draft. SN reviewed the text and proposed improvements on format and content.

\section{COMPETING INTERESTS}

The authors declare no competing interests.

\section{ADDITIONAL INFORMATION}

Correspondence and requests for materials should be addressed to PaulT.J. Scheepers

Reprints and permission information is available at http://www.nature.com/ reprints

Publisher's note Springer Nature remains neutral with regard to jurisdictional claims in published maps and institutional affiliations. 